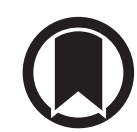

CrossMark

\section{Increased expression of ACE2, the SARS-CoV-2 entry receptor, in alveolar and bronchial epithelium of smokers and COPD subjects}

To the Editor:

Angiotensin-converting enzyme 2 (ACE2) has been identified as the cell entry receptor used by severe acute respiratory syndrome coronavirus 2 (SARS-CoV-2) [1, 2]. Importantly, smokers and patients with COPD are at an increased risk of severe complications and a higher mortality upon SARS-CoV-2 infection [3]. We hypothesised that ACE2 expression is increased in lungs of smokers and patients with COPD, which may at least partially explain their higher risk of a more severe course of coronavirus disease 2019 (COVID-19). Therefore, we aimed to investigate the expression of ACE2 on both mRNA and protein level in a large number of lung tissue specimens of well-phenotyped subjects, including never-smokers, current smokers without airflow limitation, and patients with COPD.

In this cross-sectional observational study, we analysed lung tissue specimens from 134 subjects from our large lung tissue biobank at Ghent University Hospital (Ghent, Belgium) and from explant lungs from end-stage COPD patients collected at UZ Gasthuisberg Leuven (Leuven, Belgium). Ex-smoking was defined as smoking cessation for $\geqslant 1$ year. COPD severity was defined according to the Global Initiative for Chronic Obstructive Lung Disease (GOLD) classification. Written informed consent was obtained from all subjects, and the study was approved by the medical ethical committees of Ghent University Hospital (2016/0132; 2019/0537) and the University Hospital Gasthuisberg Leuven (S51577).

RNA extraction from lung tissue blocks of 120 subjects was performed with the miRNeasy Mini kit (Qiagen, Hilden, Germany). Next, cDNA was prepared with the EvoScript Universal cDNA Master Kit (Roche, Basel, Switzerland), followed by reverse transcriptase (RT)-qPCR analysis for ACE2 and 3 reference genes, as described previously $[4,5]$.

Sections from formalin-fixed paraffin-embedded lung tissue blocks of 87 subjects were stained for ACE2. After antigen retrieval with citrate buffer (Scytek, West Logan, UT, USA), the slides were incubated with anti-ACE2 antibody (polyclonal rabbit-anti-human, Abcam ab15248). Next, slides were coloured with diaminobenzidine (Dako, Carpinteria, CA, USA) and counterstained with Mayer's haematoxylin (Sigma-Aldrich, St Louis, MO, USA). Quantitative measurements of the ACE2-positive signal in alveolar tissue and bronchial epithelium were performed on images of stained paraffin sections as described previously [6].

Statistical analysis was performed using Sigma Stat software (SPSS 26.0, Chicago, IL, USA) and R3.5.1, using Kruskal-Wallis tests (on all six groups) followed by Mann-Whitney U-tests (for the comparison between two groups), and multivariable linear regression analyses.

Using RT-PCR, ACE2 mRNA levels were determined in lung tissue from 120 subjects. ACE2 mRNA expression was significantly higher in the lung tissue of current smokers without airflow limitation and current smokers with COPD (GOLD stages II and III-IV) compared with never-smokers (figure 1a). In addition, ex-smokers without airflow limitation showed significantly lower ACE2 mRNA levels, compared with current smokers. Multivariable linear regression analysis demonstrated that current smoking and

@ERSpublications

This study demonstrates increased protein levels of ACE2 in alveolar and bronchial epithelium of smokers and subjects with COPD, which might facilitate host cell entry of SARS-CoV-2 https://bit.ly/ 2ZazOrd

Cite this article as: Jacobs M, Van Eeckhoutte HP, Wijnant SRA, et al. Increased expression of ACE2, the SARS-CoV-2 entry receptor, in alveolar and bronchial epithelium of smokers and COPD subjects. Eur Respir J 2020; 56: 2002378 [https://doi.org/10.1183/13993003.02378-2020]. 


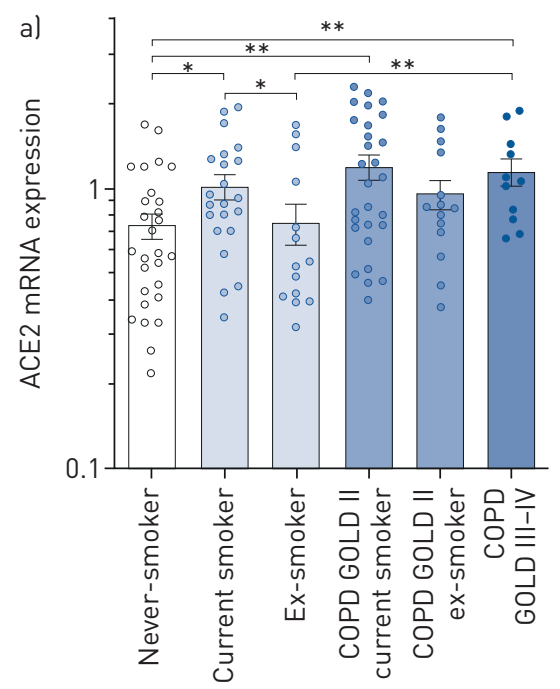

b)

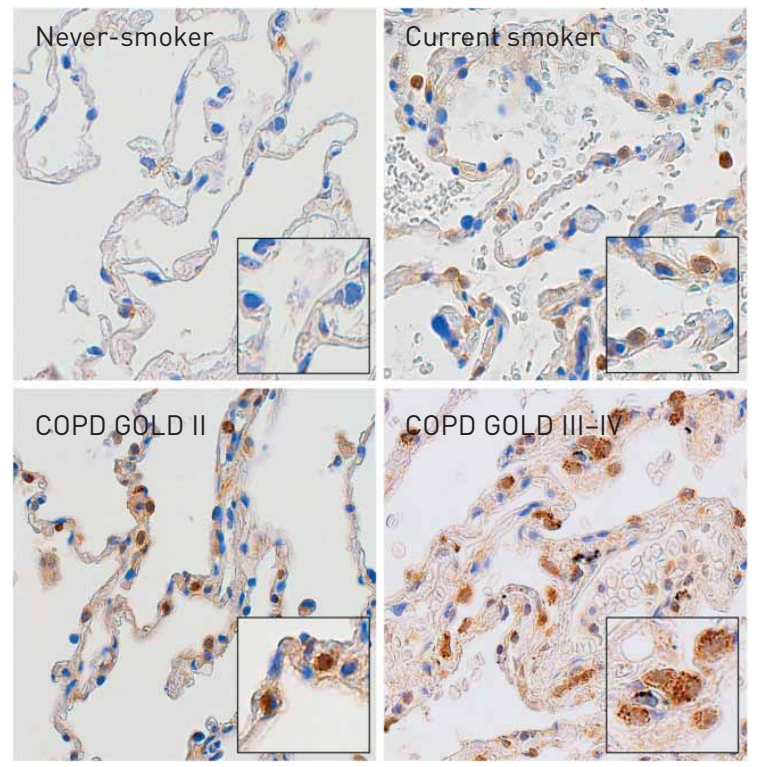

c)

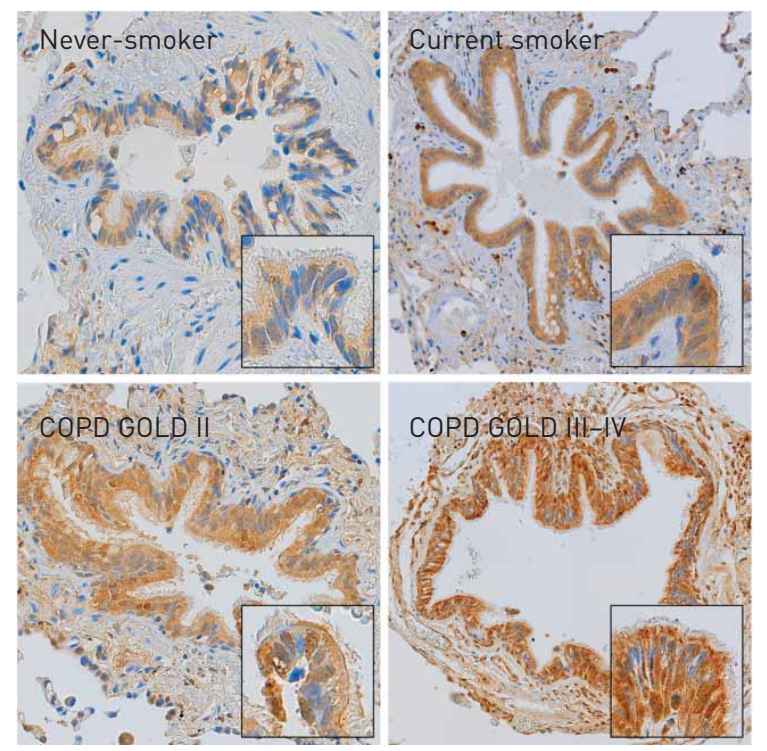

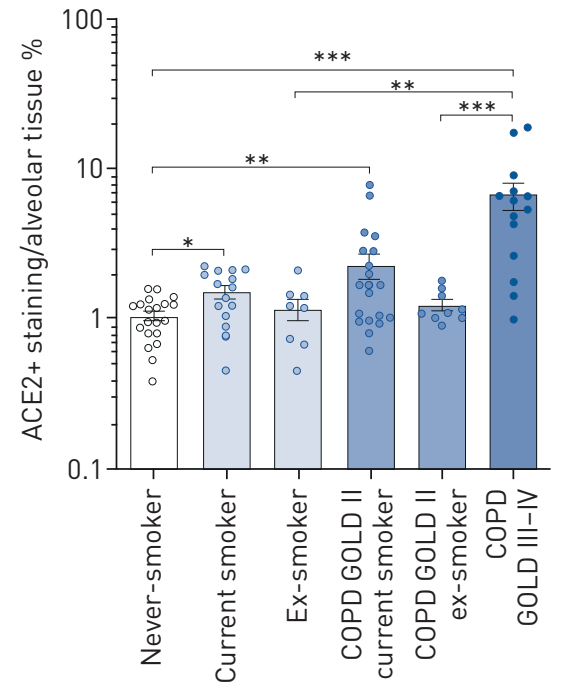

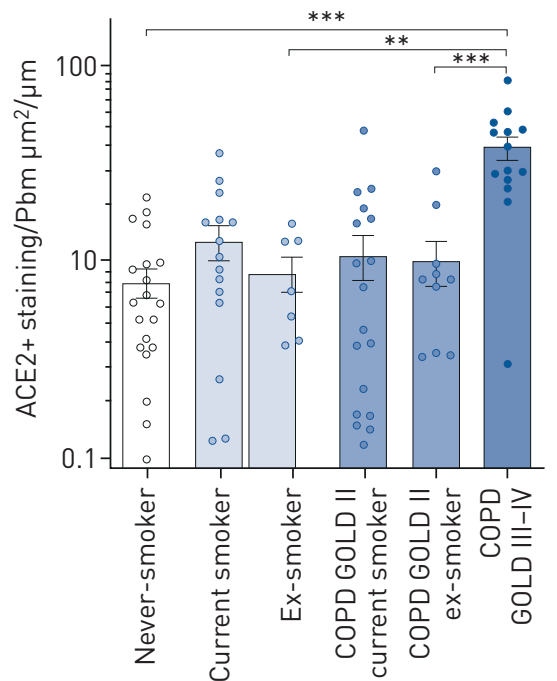


FIGURE 1 Gene and protein expression of angiotensin-converting enzyme 2 (ACE2) in the airways and lungs. a) ACE2 mRNA expression is increased in the lung tissue of smokers and COPD subjects. ACE2 mRNA expression in the lung tissue of never-, current and ex-smokers without airflow limitation and current and ex-smokers with moderate (Global Initiative of Chronic Obstructive Lung Disease (GOLD) stage II) or severe-to-very severe (GOLD stage III-IV) COPD, normalised to the expression of the housekeeping controls glyceraldehyde-3-phosphate dehydrogenase, peptidylprolyl isomerase A and succinate dehydrogenase complex flavoprotein subunit A. b) ACE2 protein levels are increased in the alveolar tissue of smokers and COPD subjects. Representative images and quantification of ACE2 immunohistochemical staining in the alveolar tissue of never-smokers, smokers without airflow limitation, smokers with COPD GOLD stage II and smokers with COPD GOLD stage IIIIV. The area of ACE2-positive signal was normalised to the total area of alveolar tissue present in each analysed image. c) ACE2 protein levels are increased in the bronchial epithelium of smokers and COPD subjects. Representative images and quantification of ACE2 immunohistochemical staining in the bronchial epithelium of never-smokers, smokers without airflow limitation and smokers with COPD (GOLD stages II and III-IV). The area of ACE2-positive signal in each airway was normalised to the length of the basement membrane (Pbm). Data are presented as means \pm SEM. *. $p<0.05 ;^{* *}: p<0.01 ; * * *: p<0.001$.

COPD are both independently associated with increased ACE2 mRNA expression in lung tissue, even after adjustment for covariates, including age, sex, body mass index and arterial hypertension (data not shown).

Through immunohistochemical (IHC) staining, ACE2 protein levels were assessed in lung tissue from 87 subjects. ACE2 IHC revealed positive staining in both bronchial and alveolar epithelial cells, with the latter predominantly in alveolar type II cells (figure $1 \mathrm{~b}$ and c). Quantification of ACE2 protein levels in the alveolar tissue revealed a significantly higher percentage of ACE2-positive alveolar tissue in current smokers without airflow limitation and current smokers with COPD (GOLD stages II and III-IV) compared with never-smokers (figure 1b). Moreover, the percentage of ACE2-positive alveolar tissue was significantly higher in patients with COPD GOLD stage III-IV, compared with ex-smokers without airflow limitation and ex-smokers with COPD GOLD stage II (figure 1b). Quantification of ACE2 staining in the bronchial epithelium revealed numerically higher levels in current smokers without airflow limitation and current smokers with COPD GOLD stage II, and significantly higher levels in patients with COPD GOLD stage III-IV, compared with never-smokers (figure 1c). Moreover, ACE2 protein levels in the bronchial epithelium were significantly higher in patients with COPD GOLD stage III-IV, compared with ex-smokers without airflow limitation and ex-smokers with COPD GOLD stage II (figure 1c). The observed association between COPD and ACE2 protein expression in alveolar tissue or bronchial epithelium remained significant after adjustment for possible confounders (data not shown).

As healthcare systems around the world are currently under great pressure due to the COVID-19 outbreak, identification of those at high risk is crucial. There is compelling evidence of a more severe course of COVID-19 in smokers and patients with comorbidities such as COPD. We clearly demonstrate an increased pulmonary expression of the SARS-CoV-2 entry receptor ACE2 in smokers and COPD subjects at both mRNA and protein level. While our observations complement previous reports on increased ACE2 mRNA and protein levels in whole lung tissue and bronchial epithelium [7-10], this is the first study demonstrating increased ACE2 protein in the alveolar epithelium of smokers and patients with COPD, which can be directly linked to the site of injury when patients with severe COVID-19 develop dyspnoea, hypoxia and pneumonia.

Currently, published data on COVID-19 in patients with COPD is fairly limited [11]. Nevertheless, an increased risk of developing severe COVID-19 as well as a higher mortality, has been reported in patients with COPD and in current smokers [3, 12]. Although there are several possible explanations for the increased susceptibility of severe COVID-19 in patients with COPD, including older age, comorbidities, dysregulated immune defences and impaired mucociliary clearance, increased pulmonary expression of the SARS-CoV-2 entry receptor ACE2 is most likely another contributor [13]. Importantly, it has been demonstrated in mouse models that transgenic (over)expression of human ACE2 enhances the pathogenicity of SARS-CoV-1 and SARS-CoV-2 [14]. Moreover, human ACE2 was essential for viral replication in the lung.

The main strength of this study is the large number of lung tissue samples from well-phenotyped subjects that are included in the RT-PCR and IHC analyses. Moreover, IHC allowed us to quantify ACE2 protein levels in both bronchial and alveolar epithelium. However, certain limitations should be kept in mind. First, this study consists mainly of samples from lung resections for pulmonary tumours. This may introduce selection bias, as altered expression of ACE2 in lung cancer has been suggested [15]. Secondly, samples of (very) severe COPD originate from a different patient population (lung transplantation), for which smoking cessation was an inclusion criterium. Finally, as we did not study lung tissue samples from COVID-19-positive subjects, we can only speculate on the importance of increased ACE2 in the pathogenicity of SARS-CoV-2.

In conclusion, we report higher ACE2 mRNA and protein levels in lung tissue of smokers and subjects with moderate-to-(very)-severe COPD. Importantly, ACE2 protein levels are not only increased in 
bronchial but also in alveolar epithelium. Further research is needed to elucidate whether upregulation of ACE2 expression in airways and lungs has consequences for the infectivity and clinical outcome of COVID-19.

Merel Jacobs $\oplus^{1}$, Hannelore P. Van Eeckhoutte ${ }^{1}$, Sara R.A. Wijnant $\oplus^{1,2,3}$, Wim Janssens $\oplus^{4}$, Guy F. Joos $\oplus^{1}$, Guy G. Brusselle $\oplus^{1,2,5}$ and Ken R. Bracke ${ }^{1}$

${ }^{1}$ Laboratory for Translational Research in Obstructive Pulmonary Diseases, Dept of Respiratory Medicine, Ghent University Hospital, Ghent, Belgium. ${ }^{2}$ Dept of Epidemiology, Erasmus Medical Center, Rotterdam, The Netherlands. ${ }^{3}$ Dept of Bioanalysis, Faculty of Pharmaceutical Sciences, Ghent University, Ghent, Belgium. ${ }^{4}$ Respiratory Division and Rehabilitation, University Hospital Leuven, Leuven, Belgium. ${ }^{5}$ Dept of Respiratory Diseases, Erasmus Medical Center, Rotterdam, The Netherlands.

Correspondence: Ken R. Bracke, Dept of Respiratory Medicine, Ghent University Hospital, Corneel Heymanslaan 10, 9000 Ghent, Belgium. E-mail: ken.bracke@UGent.be

Received: 26 May 2020 | Accepted after revision: 19 June 2020

Conflict of interest: M. Jacobs has nothing to disclose. H.P. Van Eeckhoutte has nothing to disclose. S.R.A. Wijnant has nothing to disclose. G.F. Joos reports grants from AstraZeneca and Chiesi, personal fees for consultancy from Bayer and Eureca vzw, grants and personal fees for lectures and consultancy from GlaxoSmithKline, personal fees for lectures from Teva, outside the submitted work; all fees were paid to the department. W. Janssens reports grants from AstraZeneca and Chiesi. G.G. Brusselle reports personal fees for advisory board work and lectures from AstraZeneca, Boehringer Ingelheim, Chiesi, GlaxoSmithKline, Novartis and Teva, personal fees for advisory board work from Sanofi, outside the submitted work. K.R. Bracke has nothing to disclose.

Support statement: The research described in this article was supported by the Concerted Research Action of the Ghent University (BOF/GOA 01G00819) and by the Fund for Scientific Research in Flanders (FWO Vlaanderen, G052518N and EOS-contract G0G2318N). Funding information for this article has been deposited with the Crossref Funder Registry.

\section{References}

$1 \mathrm{Xu}$ X, Chen $\mathrm{P}$, Wang J, et al. Evolution of the novel coronavirus from the ongoing Wuhan outbreak and modeling of its spike protein for risk of human transmission. Sci China Life Sci 2020; 63: 457-460.

2 Zhou P, Yang XL, Wang XG, et al. A pneumonia outbreak associated with a new coronavirus of probable bat origin. Nature 2020; 579: 270-273.

3 Alqahtani JS, Oyelade T, Aldhahir AM, et al. Prevalence, severity and mortality associated with COPD and smoking in patients with COVID-19: a rapid systematic review and meta-analysis. PLoS One 2020; 15: e0233147.

4 Seys LJ, Verhamme FM, Schinwald A, et al. Role of B cell-activating factor in chronic obstructive pulmonary disease. Am J Respir Crit Care Med 2015; 192: 706-718.

5 Conickx G, Mestdagh P, Avila Cobos F, et al. MicroRNA profiling reveals a role for microRNA-218-5p in the pathogenesis of chronic obstructive pulmonary disease. Am J Respir Crit Care Med 2017; 195: 43-56.

6 Seys LJM, Widagdo W, Verhamme FM, et al. DPP4, the Middle East respiratory syndrome coronavirus receptor, is upregulated in lungs of smokers and chronic obstructive pulmonary disease patients. Clin Infect Dis 2018; 66: $45-53$.

7 Leung JM, Yang CX, Tam A, et al. ACE-2 expression in the small airway epithelia of smokers and COPD patients: implications for COVID-19. Eur Respir J 2020; 55: 2000688.

8 Cai G, Bossé Y, Xiao F, et al. Tobacco smoking increases the lung gene expression of ACE2, the receptor of SARS-CoV-2. Am J Respir Crit Care Med 2020; 201: 1557-1559.

9 Milne S, Yang CX, Timens W, et al. SARS-CoV-2 receptor ACE2 gene expression and RAAS inhibitors. Lancet Respir Med 2020; 8: e50-e51.

10 Zhang H, Rostami MR, Leopold PL, et al. Expression of the SARS-CoV-2 ACE2 receptor in the human airway epithelium. Am J Respir Crit Care Med 2020; 202: 219-229.

11 Tal-Singer R, Crapo JD. COPD at the time of COVID-19: a COPD foundation perspective. Chronic Obstr Pulm Dis 2020; 7: 73-75.

12 Zhao Q, Meng M, Kumar R, et al. The impact of COPD and smoking history on the severity of COVID-19: a systemic review and meta-analysis. J Med Virol 2020; in press [https://doi.org/10.1002/jmv.25889].

13 Lan J, Ge J, Yu J, et al. Structure of the SARS-CoV-2 spike receptor-binding domain bound to the ACE2 receptor. Nature 2020; 581: 215-220.

14 Bao L, Deng W, Huang B, et al. The pathogenicity of SARS-CoV-2 in hACE2 transgenic mice. Nature 2020; 583: 830-833.

15 Chai P, Yu J, Ge S, et al. Genetic alteration, RNA expression, and DNA methylation profiling of coronavirus disease 2019 (COVID-19) receptor ACE2 in malignancies: a pan-cancer analysis. J Hematol Oncol 2020; 13: 43. 